International Journal of Instruction e-ISSN: 1308-1470 • www.e-iji.net

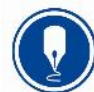

January $2022 \bullet$ Vol.15, No.1

p-ISSN: 1694-609X

pp. $873-890$

Article submission code:

2021012512_1022
Received: 25/01/2021

Revision: 15/08/2021
Accepted: 10/09/2021

OnlineFirst: 05/12/2021

\title{
Reaping the Rewards of Professional Development: Evidence from Mathematics Teachers' Pedagogical Practices
}

\author{
Mantlhake J. Maboya \\ Dr., Department of Basic Education, Pretoria, South Africa, \\ mamiki.maboya73@gmail.com
}

\section{Loyiso C. Jita}

Prof., Faculty of Education, Natural Sciences and Technology Education, University of the Free State, South Africa, jitalc@ufs.ac.za

\section{Godsend T. Chimbi}

Dr., corresponding author, Faculty of Education, Natural Sciences and Technology Education, University of the Free State, South Africa,ChimbiGT@ufs.ac.za

Teachers cannot escape being learners if they are to be proficient practitioners. This study interrogates the effects of a professional development programme on mathematics teachers' pedagogical practices in South African primary schools. Using critical theory as the illuminating lens, this qualitative study, which is cast within the participatory action research paradigm, examined mathematics teachers' classroom practices before and after a professional development programme. Data were collected from 41 mathematics teachers during the pre-intervention cycle, the intervention programme, and the post-intervention cycle. Document analysis, focus group discussion, free attitude interviews and lesson observations were the data collection tools. In the pre-intervention cycle, mathematics teachers blamed learners for errors in solving complex mathematical problems, without reflecting on their own pedagogical shortcomings. The instructional intervention programme enabled teachers to reflect more critically on their teaching methods. It also enriched their mathematical content knowledge and pedagogical skills in using manipulatives. Post-intervention lesson observations showed some improvements in the teachers' classroom practice as they reaped the benefits of the professional development programme. This study begins to demonstrate that, if properly organised, professional development activities can assist in filling gaps in teachers' content mastery and pedagogical skills; ultimately improving learner performance. The implications of this study are that teacher professional development, if aligned to teachers' pedagogical needs, can assist in improving classroom practice and is not a waste of resources as some previous studies have claimed.

Keywords: instructional intervention programme, manipulatives, post-intervention cycle, pre-intervention cycle, teacher professional development

Citation: Mabova, M. J., Jita, L. C., \& Chimbi, G. T. (2022). Reaping the rewards of professional development: evidence from mathematics teachers' pedagogical practices. International Journal of Instruction, 15(1), 873-890. https://doi.org/10.29333/iji.2022.15150a 


\section{INTRODUCTION}

Globally, professional development programmes are used to empower teachers with knowledge, skills and attitudes to transform and improve classroom practice. Despite massive investment in teacher professional development (TPD) programmes, learner performance in mathematics remains a global challenge. Many studies point to students' poor performance in mathematics (Carbonneau et al., 2018; Larbi \& Mavis, 2016; Strom, 2009; Syafriafdi et al., 2019). International assessment initiatives like Trends in International Mathematics and Science Study (TIMSS) and the Programme for International Student Assessment (PISA) have shown that students' performance in mathematics has either stalled or declined in recent years, despite increased expenditure per student by many governments (Smith et al., 2018). Declining student performance in mathematics has been reported in developed countries such as the USA (Carbonneau et al., 2013); Canada (Amy Lee, 2017); the United Kingdom (Mirza \& Hussain, 2018) and Australia (Smith et al, 2018), among others. Students' persisting poor performance in mathematics has led some scholars (Gemeda et al., 2014; Gore \& Rosser, 2020) to argue that TPD is not improving classroom practice and, therefore, is a waste of resources. Gemeda et al. (2014, p. 73) observe that: "research studies claim that teacher professional development has failed to live up to its improvement promise globally...teacher professional development is, generally, not meeting the needs of teachers in most countries." The current study intends to demonstrate that, if properly organised and aligned to teachers' pedagogical needs, professional development can improve classroom practice; affording teachers the opportunity to reap the rewards of learning new instructional practices while on the job.

\section{Review of Literature}

\section{Mathematics as a Difficult Subject}

The poor performance of students in mathematics is a global challenge (Carbonneau et al., 2018; Larbi \& Mavis, 2016; Syafriafdi et al., 2019; Strom, 2009). In a multi-country survey, $57 \%$ of eighth graders in the USA failed to meet international standards of mathematics proficiency and were ranked lowest among eight countries (Carbonneau et al., 2013). Shirvani (2015, p. 133) also observes that: "Students in the United States do not perform well in mathematics compared with most industrial nations." The performance of Australian learners in Trends in International Mathematics and Science Study (TIMSS) and the Programme for International Student Assessment (PISA) has either stalled or declined in recent years, despite increased government spending per student (Smith et al. 2018). In Canada a downward trend in students' mathematics performance in TIMSS and PISA has been recorded since 2003 (Amy Lee, 2017). Similar trends have also been reported in the United Kingdom (Mirza \& Hussain, 2018). Countries that have consistently recorded outstanding performance in mathematics are Singapore, Republic of Korea, Chinese Taipei, Hong Kong and Japan (Reddy et al., 2016). These East-Asian countries occupied the top five positions in chronology in the 2015 TIMSS mathematics rankings, out of 39 countries. 
Students in developing countries perform far worse in mathematics than their peers in the developed world. In the 2015 TIMSS rankings of eighth and nine graders in mathematics, the lowest performing countries were from the Middle East and Africa, and the top-performers were from Asia and the Northern Hemisphere (Reddy et al. 2016). Four African countries that participated in the survey - Egypt, Botswana, Morocco and South Africa - were numbers 34, 35, 37 and 38 respectively out of 39 countries. Saudi Arabia came last. Salami and Okeke (2017, p. 47) remark that "African countries' performance in mathematics appears much poorer than elsewhere in the world."

The poor performance of students in international assessments has led to claims that TPD, not only in Africa but the world over, is not improving teachers' pedagogical practices, so it is a waste of resources (Dehghan, 2020; Gemeda et al., 2014; Gore \& Rosser, 2020; OECD, 2009). Gemeda et al (2014) point out that most research studies claim that professional development has failed to improve classroom practice globally as most teachers continue to use rote pedagogy though policy advocates for learnercentredness. The reason for this failure, according to Gemeda et al (2014), is the topdown, one-shot approach which is often used to revatilise teachers' classroom practice. But other scholars, like George et al. (2018) and Venkat and Spaull (2015), place the blame on teachers' poor mathematics content and pedagogical knowledge.

\section{Mathematics Teachers' Pedagogical Practice}

Research has consistently shown that mathematics teachers generally use teachercentred methods. Salami \& Okeke $(2017$, p. 48) remark that "Poor quality instructional technique is one of the major causes of poor achievement in mathematics...nonprovision of an activity-oriented and pupil-centred lesson, which could demystify the teaching and learning of the subject, is the main reason for the poor performance." The commonest approach is for the teacher to introduce a new concept while students listen passively, demonstrate on the chalkboard how the concept is used to solve a mathematical problem and get the correct answer. Sometimes the teacher asks learners if they have any questions. In most cases students do not ask anything. They pretend they have understood.

The teacher may illustrate a second example on the board and then ask learners to copy the examples into their notebooks. Learners are then assigned new mathematics problems to solve. Most students learn mathematics "through memorising definitions and recalling some loosely connected facts, mostly because the teachers themselves could not understand those concepts hence make the learners recite them like a poem" (George et al., 2018, p. 10). Teachers' poor content knowledge of mathematics has led to calls for professional development across the globe.

\section{The Need for Teacher Professional Development}

Research into the root causes of students' underachievement in mathematics has brought teachers' mathematics content knowledge under spotlight. Different studies show that mathematics is a difficult subject; not only for learners, but for teachers as well (Foley et al., 2017; Hidayah et al., 2018; Jita \& Ige, 2019; Venkat \& Spaull, 2015). In Texas 
(USA) pre-service teachers performed lowest in a test on measurement in mathematics (Shirvani, 2015). Hidayah et al. (2018) administered a two planar geometry test requiring one-word answers to 29 elementary school teachers in Indonesia. Only $38 \%$ got correct answers, $34 \%$ gave wrong responses and $28 \%$ did not respond.

In a multi-country study conducted in primary schools in seven sub-Saharan African countries (Uganda, Kenya, Tanzania, Mozambique, Nigeria, Senegal and Togo), Bold et al. (2017, p. 3) found that: "teachers' subject knowledge is strikingly low... about a quarter of the teachers fail simple tasks such as subtracting two-digit numbers." Overall, one in ten mathematics teachers could not add four-digit numbers. Only 60\% of the teachers in Nigeria and Mozambique could subtract double digits. In Togo, only $30 \%$ of the teachers could solve a simple math story problem (Bold et al., 2017, p. 12). In Lesotho, George et al. (2018, p. 14) asked 107 primary school teachers to rate their performance in teaching mathematics and 14\% rated themselves as "poorly performing." Of the 107 teachers, $32 \%$ had failed mathematics at the school leaving certificate and $23 \%$ had not taken the subject at that level, although they were all teaching mathematics.

Studies conducted in South Africa also point to teachers and students' poor mathematics content knowledge (Jita \& Mokhele, 2014; Jita \& Ige, 2019; Tachie, 2020; Venkat \& Spaull, 2015). For instance, Jita \& Ige (2019, p. 705) remark that "the disappointing performance of South African school children in Science and Mathematics in Trends in International Mathematics Education (TIMSS) needed urgent attention from academic researchers." This triggered TPD initiatives to improve the subject-content of South African mathematics teachers; like the Mpumalanga Secondary Science Initiative (Jita \& Mokhele, 2014), and the Short Learning Intervention Programme (SLIP) (Jita \& Ige, 2019). In a study by Tachie (2020), one South African teacher admitted that; "All along I have been struggling teaching some of the topics in class" (p. 2332). Another teacher added: "Some of the teachers have been experiencing problems with the concepts to be taught." Through lesson study, the teachers in Tachie's study realised the need for content mastery if they were to teach mathematics proficiently. Teachers' poor mathematics content knowledge may partly explain why students underperform in the subject.

South African mathematics teachers' inadequate content knowledge necessitated the Instructional Intervention Programme (IIP) being examined in this paper. The aim of the IPP was to improve primary school mathematics teachers' content knowledge and the use of manipulatives to teach the subject in the Free State Province of South Africa. The researchers organised and facilitated the IIP to revatilise the way mathematics is taught in primary schools, in the hope that this would improving learner performance. Most existing studies (Carbonneau et al., 2018; George et al., 2018; Larbi \& Mavis, 2016; Salami \& Okeke, 2017; Syafriafdi et al., 2019) concentrated on the shortcomings of professional development programmes and how they have largely failed to change the way teachers teach. There is a paucity of research on how teachers have benefited from TPD. The current study seeks to add new insights on how well coordinated interventions can generate affordances for teachers to reap rewards from TPD. By learning new instructional strategies while on the job, teachers can subsequently utilise new 
methodologies to improve classroom practice in mathematics, a subject that has proved to be difficult for both teachers and students.

\section{Theoretical Framework}

The current study taps into critical theory as its illuminating lens. Critical theorists call for the transformation of the world to benefit marginalised and poorly remunerated groups like teachers (Apple, 2004). Ozlem and diAngelo (2017, p. 25) point out that: "Critical theory's analysis of how society works continues to expand and deepen as theorists from indigenous, postcolonial, radicalised and other marginalized perspectives add layers to our collective understanding." Critical theory was found appropriate in shading insights into how professional development programmes empower teachers to construct, deconstruct and reconstruct knowledge. Over the past decades, TPD has come under severe criticism; mainly because "governments worldwide invest billions in teacher PD annually with the intention of enhancing teachers' knowledge and practice... Yet, to date, few studies have shown rigorous evidence of the impact of PD on teachers and their practice - let alone student outcomes" (Gore \& Rosser, 2020, p. 1). Critical theory provided opportunities for the current study to examine how a professional development programme can improve (or can fail to change) classroom practice.

\section{Research Context}

This study sought to empirically explore the claim that TPD seems not to improve classroom practice by examining mathematics teachers' pedagogical practice before and after an Instructional Intervention Programme (IIP). The IIP sought to enrich South African teachers' content knowledge of complex mathematical concepts and their pedagogical skills in using manipulatives to teach the abstract and often confusing concepts. The objectives of the paper, therefore, are two-fold: to examine South African mathematics teachers' pedagogical practices before the IIP; and tease out the changes, if any, in teachers' classroom practices after undergoing TPD. In line with these objectives, two research questions direct this paper:

1. How did mathematics teachers conduct their lessons before the Instructional Intervention Programme (IIP)?

2. To what extent did the IIP bring changes in mathematics teachers' classroom practices, if at all?

\section{METHOD}

\section{Research Design}

Based on the premise that knowledge is power, and that knowledge and action are intricately connected, the current study adopts a qualitative participatory action research design. Participatory action research (PAR) involves researchers and participants working together to understand a common problem and generate solutions that can bring change for the better (Neuman, 2014). PAR empowers teachers with new knowledge and skills to improve competencies. It fosters classroom change that "promotes democracy and challenges inequality...so that participants have a greater awareness of their situation in order to take action" (Institute of Development Studies, 2013, p. 1). 
PAR is consistent with critical theory which illuminates this study. This research design aims at transforming mathematics teachers' knowledge and classroom practices so that mathematics can be comprehensible to all learners, irrespective of their aptitudes and social class backgrounds.

\section{Site Settings}

This study involved 19 primary schools that participated in the Instructional Intervention Programme (IIP) in the Motheo Education District of the Free State in South Africa. The programme was initiated by the first researcher as part of her $\mathrm{PhD}$ research with the University of the Free State. The IIP was rolled out in collaboration with the Free State Department of Education (FSDoE). The mathematics teachers from 19 primary schools actively participated in the IIP which aimed at improving their subject-content mastery and improving the use of manipulatives in lesson delivery. The programme was conducted over a three months period, from April to June 2013.

\section{Participants and Sampling}

Forty-one mathematics teachers from 19 primary schools were the research participants in the study. The 41 teachers participated in the Focus Group Discussion and the IIP workshop which was held mid-way through the data collection process. Purposive sampling was used to select three schools from which three Grade 6 teachers were case studied during the pre-intervention and post-intervention data collection cycles. The three selected schools were township schools with learners from disadvantaged backgrounds. The schools were built after South Africa's independence (1994). Each sampled school had a fully equipped mathematics laboratory with 10 fixed tables that could accommodate four learners each, 10 computers, a data projector, a pull-down projector screen and a whiteboard. Manipulatives such as interlocking cubes, multi-base blocks, fraction charts, tangrams, geometric shapes, teaching clocks and chess board printed carpets were the defining features of the mathematics laboratories. One teacher was selected from each of the three sampled primary schools. The sampled teacher had more than five years' experience teaching mathematics at Grade 6 level, volunteered to participate in the IIP and was willing to be observed and video-recorded in the preintervention and post-intervention phases of the study.

\section{Data Collection Tools}

Four data collection instruments were utilised. Document analysis was used to examine the Curriculum and Assessment Policy Statement (DBE, 2011) and determine how it empowered (or disempowered) teachers. A focus group discussion (FGD) was conducted and audio recorded with the 41 teachers on the challenges they faced in teaching mathematics at the Intermediate Phase (Grade 4 to 6). Free Attitude Interviews (Neuman, 2014) were conducted with each of the three teachers sampled as case studies. The interview protocol was developed by the first researcher and examined by the research supervisor and a FSDoE official to ensure that the questions asked were aligned to the research questions and would generate responses which answered these questions. Using recommendations from these two experts, the first researcher refined the interview questions before conducting the interviews with the three purposively sampled 
teachers. These interviews generated unconstrained conversations between the first researcher and the participants on subject-content mastery and the value of manipulatives as instructional tools in mathematics lessons. Pre-intervention and postintervention lesson observations were video recorded in each of the three teachers' mathematics laboratories.

\section{Data Collection Cycles}

Data collection in this PAR study unfolded in three phases: the pre-intervention cycle, the intervention programme, and the post-intervention cycle. The pre-intervention cycle started with a focus group discussion (FGD) involving all the 41 teachers participating in this study. The discussion was audio recorded and field notes taken. The FGD focused on errors made by students in learning mathematics and the problems teachers faced in teaching the subject at the Intermediate Phase (Grade 4 to 6). The strategies that can be used to correct students' errors were also discussed. Free Attitude Interviews were also conducted with each of the three selected Grade 6 teachers. Pre-intervention lesson observations were video recorded in each teacher's mathematics laboratory.

An IIP workshop was held mid-way through the data collection period. The workshop addressed some of the challenges that emerged during the FGD and the pre-intervention lesson observations. The IIP workshop was held on a Saturday for 6 hours, excluding the convenience and lunch hour breaks. It unpacked the challenges mathematics teachers faced in teaching the multiplication of multi-digit numbers and fractions. Demonstration lessons were held on how teachers can use manipulatives when teaching multi-digit multiplication and fractions. After the demonstration lessons content-enrichment sessions were held to improve the teachers' subject-content.

The post-intervention cycle was conducted after the IIP workshop. It gathered data on how teachers had changed their pedagogical practice after the intervention programme, if at all. Post-intervention lesson observations were video recorded for later analysis and transcription.

\section{Data Analysis}

The audio recorded FGD, Free Attitude Interviews, fieldnotes and summaries from policy documents were transcribed using a Microsoft-Word processor and printed. Hard copies of the transcriptions were analysed iteratively. Initial analysis involved making sense of what participants had said. Information considered irrelevant was put aside in case it would be needed (Neuman 2014). Evidence from the FGD, interviews and fieldnotes (deemed relevant to the research questions) was categorised, manually coded, tabulated, and reduced to manageable units. Transcriptions from policy documents were also analysed to separate the important from the trivial and gain insights into policy expectations.

Transcriptions from video-recorded lesson observations were examined, coded, categorised and sythesised to pick commonalities and unique practices. Data from lesson observations were triangulated with those from interviews, documents and the FGD to check for authenticity, consistency, similarities, and uniqueness. Evidence from the four 
sources was then aggregated and crystallised to generate themes on how mathematics teachers taught before and after the IIP workshop. The findings emerging from the data analysis are presented in the next section.

\section{FINDINGS}

Findings on how teachers taught mathematics before and after an Instructional Intervention Programme (IIP) in the Motheo Education District of the Free State Province in South Africa are presented under four major themes: Identifying roots of the problem; manifestations of the problem; Instructional Intervention Programme; and rewards of intervention.

\section{Identifying Roots of the Problem}

The FGD brought together 41 Intermediate Phase mathematics teachers who participated in the IIP. The first researcher distributed reports generated from two error analysis workshops conducted with mathematics teachers a year before the intervention programme. Participants were given time to study the reports. To stimulate discussion, the researcher also handed out copies of an article titled "Teachers are clueless" (Child, 2013). The article claimed that: "teachers' poor subject knowledge was arguably the fundamental problem in the school system...many teachers did not know how to inculcate problem-solving and analysis skills" (p. 1). Heated debate emerged among participants. Excerpts:

$\mathrm{T}_{1}$ : I think it is not fair to say that teachers do not know what they are doing when they are trained for the job.

$\mathrm{T}_{2}$ : The problem is that sometimes teachers are judged by people who have never been in the classroom or left teaching many years ago.

$T_{3}$ : Teachers are demotivated because of the low salaries they get when their work is so demanding, and classes are too large.

$\mathrm{T}_{4}$ : Teaching has never been easy because the language we use in the class is not ours. So, learners must first learn the language before they can learn the concepts.

Some common challenges that affect teachers' classroom practices emerged out of this discussion. The language of instruction (English) is not the mother-tongue for most black South Africans, which makes it difficult for learners to comprehend what is being taught. The teachers also complained that poor remuneration demotivated them and classes were often over-loaded.

The FGD then moved on to common errors made by students in multiplying multiple digit numbers and fractions. The teachers were given three tasks: to identify the errors students made; find possible causes for the errors; and suggest intervention strategies to correct the errors. The teachers' responses were mainly generic and surface level. Some of the responses that emerged:

$\mathrm{T}_{1}$ : Learners cannot multiply two-digit numbers because to them multiplication and addition are the same. They tend to mix these two. 
$\mathrm{T}_{2}$ : Learners lack the basic knowledge on how whole numbers differ from fractions.

$\mathrm{T}_{3}$ : Students carry these problems from lower grades where these concepts are introduced.

Teachers seemed to place all the blame on learners without reflecting on their pedagogical shortcomings when they teach these concepts. Consequently, most of the interventions they suggested did not address the fundamental problems undergirding students' errors. As the discussion unfolded, the teachers indicated that, sometimes, they had insufficient knowledge of the concepts they taught. Some of their observations were:

$\mathrm{T}_{1}$ : Fractions are always difficult to teach from Grades 4 to 6 , especially improper fractions. Improper fractions mix whole numbers and fractions. This can confuse teachers, what more learners?

$\mathrm{T}_{2}$ : At primary school teachers are made to teach mathematics even when they failed the subject at school. So, it may not be the learners' fault.

$\mathrm{T}_{3}$ : It may not be the Grade 5 or Grade 6 teacher's fault. It's the system which assumes that every teacher can teach mathematics.

Although some teachers placed the blame on learners and the system, eventually there was consensus in the FGD that teachers often lack mathematical content knowledge.

The lack of mathematical content knowledge also emerged in the pre-observation interviews. Ms Bohata explained that; "I never did mathematics at matric. I only did it up to Junior Certificate level (equivalent to Grade 9) because we were always reminded that mathematics is not for the faint hearted." Ms Bohata was now teaching mathematics, a subject she was afraid to take at secondary school. Ms Dikgomo also narrated that: "I trained as a teacher for the Foundation Phase Grades 1 to 3...I only started teaching mathematics at the Intermediate Phase because the School Principal spotted me as someone who had a clue of mathematics." It was only Mr Kopung who seemed to have adequate mathematical content knowledge and appropriate training to teach mathematics at Grade Six. He explained that: "I was good in mathematics at high school and I trained as a mathematics teacher." The teacher's content knowledge, or lack of it, is likely to affect pedagogical practice.

\section{Manifestations of the Problem}

The pre-intervention lesson observations reflected some of the challenges mathematics teachers talked about in the FGD and the interviews. They also scaffolded observations made in previous studies that some mathematics teachers' content knowledge was poor. Ms Dikgomo taught a lesson on multiple operations. Excerpts:

$\mathrm{T}$ : What are the four basic operations?

$\mathrm{L}_{1}$ : Addition, multiplication, subtraction and division.

T: But we still have other operations. Can somebody remind us of that rule?

$\mathrm{L}_{2}$ : The BODMAS rule Ma'am. [Teacher wrote the word on the whiteboard] 
T: What are the other two operations?

$\mathrm{L}_{3}$ : Brackets and of.

T: Mathematicians developed the BODMAS rule so that we don't get different answers. Mathematics is about following the rules; if we don't there will be chaos. I'm going to show you how different answers can cause chaos.

[The teacher showed a video clip of motorists not obeying road rules. Accidents occurred. Learners watched in fascination]

Ms Dikgomo emphasised the need for rules and correct answers in mathematics; reflecting her belief that mathematics is a set of rules and procedures. The video clip was a powerful illustration that mathematics consists of fixed rules. Students were likely to remember this long after the lesson. Ms Dikgomo's practice contradicted critical theory, which is the guiding lens for the current study. Critical theory advocates learner empowerment with knowledge so that they solve problems on their own, with the teacher facilitating the process (Ozlem \& diAngelo, 2017). But Ms Dikgomo's approach to number operations reinforced the "pedagogy of the oppressed" (Freire, 1970). She was the "narrating subject" and learners were "listening objects" (p. 71). She seemed to overlook the need for learners to understand the rationale behind the rules. Learners had to accept the rules as given with no opportunity to question or investigate.

Ms Bohata introduced three-dimensional (3D) shapes using learners' existing knowledge, which was an appropriate and commendable approach. Highlights from the lesson:

$\mathrm{T}$ : Who can give me an example of a $2 \mathrm{D}$ shape?

$\mathrm{L}_{1}$ : Square [Teacher wrote the word on the whiteboard]

T: Another 2D shape?

$\mathrm{L}_{2}$ : Oval [Teacher was hesitant to write the answer on the board]

T: Not exactly. But rectangle! [She wrote 'rectangle' on the board]

The learner gave an example of an oval as a 2D shape. But Ms Bohata brushed aside the unanticipated answer. Instead of explaining why she was rejecting the answer, she went on to give her own example of a what she considered the correct answer. It appears she wanted learners to respond according to her expectations. Ms Bohata regarded herself as the only source of 'correct knowledge.' This approach was against the critical perspective which sees learners as active creators of new knowledge, rather than passive recipients of processed information (Apple, 2004). The learner's answer was correct but Ms Bohata rejected it; reflecting her own poor content mastery of 2D shapes.

Mr Kopung's lesson was an introduction to 2D shapes. He opened the lesson with a question and answer session.

T: What shape is this table? 
$\mathrm{L}_{1}$ : A rectangle.

T: How many sides does a rectangle have?

$\mathrm{L}_{2}$ : Four sides.

$\mathrm{T}$ : Is this table also a square?

Ls: [In chorus] No, teacher! It is a rectangle!

$\mathrm{T}$ : What is the difference between a square and rectangle?

$\mathrm{L}_{3}$ : A square has four equal sides and a rectangle has only two sides that are equal.

$\mathrm{T}$ : Which of those two sides are equal?

$\mathrm{L}_{4}$ : The upper and the bottom sides [pointing at the longer sides of the table]

$\mathrm{L}_{5}$ : The left side and the right side! [Pointing at the shorter sides]

T: In mathematics, we say the bottom side is opposite the upper side. The left side is opposite the right side. So, the opposite sides of a rectangle are equal. [Writes the rule on the whiteboard] What about in a square?

$\mathrm{L}_{6}$ : All sides are equal [Writes the rule on the board]

Mr Kopung helped learners develop appropriate mathematical language as they moved from the simple concept of four equal sides in a square to the more complex concept of equal but opposite sides in a rectangle. But he did not make use of any concrete manipulatives to illustrate the mathematical concepts, although he was conducting the lesson in a richly stocked mathematics laboratory.

\section{Instructional Intervention Programme (IIP)}

The IIP was designed to address some of the pedagogical challenges teachers identified during the FGD, the pre-observation interviews and the shortcomings the first researcher observed during the pre-intervention lesson observations. This intervention programme was developed within the critical theory framework (Apple, 2004; Freire, 1970). It provided teachers the opportunity to discuss (as a group) the problems they faced in teaching mathematics at the Intermediate Phase. The IIP was a six-hour workshop divided into two sessions of three hours each. Session One focused on multi-digit multiplication. Session Two was on fractions. All the 41 mathematics teachers participated in the workshop.

The purpose of the IIP was to demonstrate the use of manipulatives as concrete instructional tools and enrich the teachers' content knowledge on multi-digit multiplication and fractions. The teachers actively participated in the construction of new knowledge which they could use to initiate pedagogical change in their mathematics lessons. The IIP was also meant to benefit less gifted learners who struggle to grasp abstract mathematical concepts like the multiplication of multi-digits numbers and fractions. The use of concrete manipulatives (which learners could see, touch and 
manipulate) to teach abstract concepts would assist students with learning difficulties in the concrete-pictorial-abstract transition in mathematics.

At the FGD, which was held two weeks before the IIP workshop, four teachers volunteered to prepare demonstration lessons; with assistance from the other mathematics teachers at their schools. Two volunteers prepared lessons on multi-digit multiplication and the other two on fractions. These lessons were presented at the IIP workshop. Those teaching multi-digit multiplication used counters, abacus, pattern blocks, colour tiles and unifix cubes as manipulatives in the demonstration lessons. Interlocking cubes, fraction circles, fraction strips, geoboards and Cuisenaire rods were used to teach fractions. Each demonstration lesson was 40 minutes long, followed by 20 minutes post-observation discussion on content mastery and the use of manipulatives. After each post-observation discussion, the first researcher facilitated content enrichment on the concepts taught for 30 minutes before moving on to the next lesson demonstration.

\section{Rewards of Intervention}

The second set of lesson observations was conducted after the IIP workshop to examine the nature of change, if any, in the teachers' mathematical content knowledge, use of manipulatives and general classroom practice.

Ms Dikgomo's lesson on fractions showed some changes in her teaching. She used manipulatives to develop students' conceptual understanding of fractions. Segments from the lesson:

T: What do you have on your tables?

$\mathrm{L}_{1}$ : Interlocking cubes, colours and papers.

$\mathrm{L}_{2}$ : And scissors.

T: I want you to use the cubes or paper, colours and scissors to show half, one-third, one-quarter and one-fifth [She wrote the fractions on the board]. Work in pairs.

Learners made concrete representations of fractions using the whole-part approach. After working on the activity, learners presented the concrete representations of specific fractions. She gave instructions: "Those who used cubes show us the fractions you created. Those who used paper show us the parts you shaded or cut. When you present the fraction, for example a half, tell us how you know it is a half; and write the fraction in figures on the board."

Learners presented blocks or pieces of paper as 'wholes' before showing the fractions. They also wrote the numeric representations on the white board. Ms Dikgomo questioned: 'How do you know this is a half, or a quarter?' Learners' answers reflected deeper understanding of fractions beyond the surface level. Ms Digkomo's practice in this lesson dovetailed with the critical theory framework which is guiding the current study. Critical pedagogy empowers learners with independent thinking skills so that they can reach their own conclusions instead of reproducing the teacher's preconceived 
opinions and subjectivities. The IIP workshop appeared to have improved Ms Dikgomo's use of manipulatives and pedagogical practice. She helped learners concretise fractions before writing the symbolic representations on the whiteboard.

After the IIP, Ms Bohata used manipulatives to teach 3D shapes. She appeared more confident, robust and flexible, compared to the pre-intervention lesson. She handed out concrete representations of rectangular and triangular prisms to learners.

$\mathrm{T}$ : Do you see any anything common on these boxes?

$\mathrm{L}_{1}$ : They have many sides and shapes.

$\mathrm{T}$ : [Holding a triangular prism] How many shapes do you see on this one?

$\mathrm{L}_{2}$ : Two triangles and three rectangles.

T: Very good. What about on the other one?

$\mathrm{L}_{3}$ : I see rectangles.

T: Yes. How may rectangles? Count them. Use this marker to number the sides.

$\mathrm{L}_{3}$ : [Numbering the sides] 1, 2, 3, 4, 5, 6

T: Good. Shapes with many sides like these we call them prisms [Writes the word on the board]

Ms Bohata used learners' existing knowledge of shapes to explore the properties of prisms. Learners physically counted the number of sides on the boxes. She then introduced the concepts of the base, the faces and the edges by marking these on the prisms. She drew pictorial representations of triangular and rectangular prisms on the whiteboard. Learners were instructed to draw the prisms in their books and label the base, the faces and the edges. Ms Bohata assisted learners' cognitive transition from concrete to pictorial representations so that they could create mental images of prisms. This instructional approach aligned well with critical theory (Freire, 1970) which advocates for learners' active participation in the search for new knowledge, rather than being reduced to passive receptacles of processed information.

Mr Kopung's post-intervention lesson was on the properties of 3D prisms. Learners had brought a variety of used containers like match boxes, juice cartons and cereal boxes. He asked students to get into pairs and handed out five, six and eight-sided boxes to each pair. Using a cube as an example, he asked learners to identify the base; and then count the number of faces, edges and vertices (corners). Mr Kopung assisted learners in completing the 'cube row' in Table 1. He then asked them to use the different manipulatives on their tables to complete the rows for the other prisms shown in the table. 
Table 1

Prism types and properties

\begin{tabular}{llllll}
\hline Prism Name & Base & Sides of the base & Faces & Edges & Vertices \\
\hline Cube & 1 & 4 & 6 & 12 & 8 \\
\hline Triangular Prism & 1 & 3 & 5 & 9 & 6 \\
\hline Pentagonal Prism & 1 & 5 & 7 & 15 & 10 \\
\hline Hexagonal Prism & 1 & 6 & 8 & 18 & 12 \\
\hline Octagonal Prism & 1 & 8 & 10 & 24 & 16 \\
\hline Rectangular Prism & 1 & 4 & 6 & 2 & 8
\end{tabular}

Using manipulatives, learners developed relationships between the base and the other features of the prism. It was fascinating for learners to discover new mathematical knowledge as they practically counted the number of faces, edges and vertices on different prisms. They also utilised pre-existing knowledge on different shapes. When learners made errors in counting the number of edges and vertices, $\mathrm{Mr}$ Kopung patiently assisted them. He provided learners the opportunity to construct, deconstruct and reconstruct knowledge, closely aligning his practice to critical theory which informs this paper. Learners corrected their mistakes by recounting the edges and vertices on the prisms they were holding. In the end they came up with correct answers. The IIP appeared to have improved Mr Kopung's use of manipulatives to concretise abstract mathematical concepts, reflecting the benefits of professional development to mathematical practice.

\section{DISCUSSION}

Some previous studies (see Dehghan, F., 2020; Gemeda et al., 2014; Gore \& Rosser, 2020; OECD, 2009, for example) have doubted the benefits of TPD in improving pedagogical practice mainly because most TPD programmes lack relevance to the challenges teachers encounter in their practice. Once a professional development programme is over, teachers often revert to their old practices. The unique findings from the current study debunk the long-held view that TPD programmes do not improve pedagogical practice and teachers do not benefit from them. The post-intervention lesson observations in the current study showed that the IIP, and the use of manipulatives it promoted, can resolve the problem of teaching mathematics using teacher-centred approaches because the three teachers were now using activity-based learner-centric strategies. In the current study Ms Dikgomo and Bohata appeared to have benefited a lot from the IIP which revatilised their content mastery and the use of manipulatives, resulting in improved classroom practice. Mr Kopung, who relied a lot on the question-and-answer method in the pre-intervention lesson (although he was teaching in a generously stocked mathematics laboratory) used manipulatives intensively in the post-intervention lesson. The three teachers' post-intervention lessons had more learner activities than teacher-talk and simple recall questions, reflecting a noticeable shift from the pre-intervention teaching approaches.

Whereas pre-intervention lessons were largely characterised by rote learning, which went against the tenets of critical pedagogy and its advocacy for learner empowerment (Apple, 2004; Freire, 1970); post-intervention instruction aligned with the critical 
perspective as the teachers created opportunities for learners to generate new knowledge and correct their own mistakes. The teachers appeared more confident in their use of manipulatives and handling of complex mathematical content showing that the shortterm IIP had revamped their mathematical content knowledge and practical pedagogical skills. The benefits of the IIP seem to resonate with those of the Short Learning Intervention Programme (SLIP) (Jita \& Ige, 2019). SLIP gave mathematics teachers the opportunity to utilise the knowledge they acquired from the short-term intervention programme to improve lesson delivery in their classes. Findings from SLIP and IIP seem to dispute the assertion by Gemeda et al. $(2014$, p. 73$)$ that "a one-shot approach to teacher professional development lacks the focus, intensity and continuity needed to change classroom practices." Insights gleaned from the IIP seem to indicate that, if properly organised and aligned to teachers' pedagogical needs and everyday challenges, short-term professional intervention programmes can be as effective as long-term professional development initiatives. In the light of the evidence emanating from the IIP, one can argue that, it is not the length of the TPD programme that matters, but the quality of the intervention.

However, some findings from the IIP seem to speak to existing literature. For instance, research by George et al. $(2018$, p. 9) in Lesotho primary schools has shown that; "there are some teachers who have never passed Mathematics and Science at any level of education examined nationally, thus making it difficult and uncomfortable for these teachers to teach these subjects effectively." Ms Bohata did not take Mathematics at Matric level. This may partly explain why she rejected the answer that an oval is a $2 \mathrm{D}$ shape. Ma (2010) points out that, what teachers expect learners to know may be an indicator of the teachers' content knowledge, or lack of it. It is not surprising, therefore, that Ms Dikgomo taught number operations using rote pedagogy in the pre-intervention lesson; although she was in a mathematics laboratory full of manipulatives which she could have utilised to concretise the abstract concepts. But after the one-day IIP Ms Dikgomo availed a variety of manipulatives to assist learners create concrete representations of different fractions before moving on the pictorial and symbolic representations of the concepts. This showed that her content knowledge and pedagogical skills had improved as a result of the short-term IIP.

\section{CONCLUSION}

The current study has shown that, if TPD is relevant to teachers' classroom needs, it can empower them with new content knowledge and pedagogical skills. The IIP enabled teachers to use activity-centred approaches that develop learners' problem-solving skills. Teachers in this study appeared to be reaping the benefits of professional development which has for some time been criticised as ineffective and a waste of resources. They were using manipulatives to promote learner-centred activities in mathematics lessons after participating in the IIP. This study has shown that, indeed, teachers cannot escape being learners because they need new knowledge to be dynamic classroom practitioners. However, the major limitation of the current study is that it was only conducted in one school district of the Free State Province, limiting the generalisability of the findings to other school districts. The second limitation is that the IIP was a short-term programme 
conducted over three months and with mathematics teachers only. Future research can focus on how long-term continuous professional development can be reframed to empower teachers with new knowledge and skills across different subjects because teachers' existing knowledge can easily become obsolete in the rapidly changing $21^{\text {st }}$ century. But still, short-term professional development programmes (to improve teachers' subject-content knowledge and pedagogical skills across all learning areas) are needed now (more than ever before) because of the rapidly changing knowledge landscape driven by the Fourth Industrial Revolution. It would be a mischievous halftruth, if not a fallacy, to assume that short-term professional development initiatives have no rewards for practicing teachers and, ultimately, learners.

\section{ACKNOWLEDGEMENTS}

This article is generated from an unpublished PhD thesis: Maboya, M.J. (2014). The relationship between teachers' mathematical knowledge and their classroom practices: A case study on the role of manipulatives in South African primary schools. University of the Free State, Bloemfontein, South Africa. https//scholar.ufs.ac.za/handle/11660/783

\section{REFERENCES}

Amy Lee, K.Y. (2017). Improving Ontario mathematics performance: A comparative study of underlying factors for mathematics achievements in Ontario-Canada, Singapore and Shanghai-China. [Unpublished master's thesis]. Harvard University. Retrieved 3 August 2020 from http://nrs.harvard.edu/urn-3:HUL.InstRepos:37736809

Apple, M.W. (2004). Ideology and Curriculum ( $3^{\text {rd }}$ edition). London: Routledge and Palmer.

Bett, H.K. (2016). The cascade model of teachers' CPD in Kenya: A time for change? Cogent Education, 3/1, 1-9. Retrieved 3 August 2020 from https://doi.org/10.1080/2331186X.2016.1139439

Bold, T., Filmer, D., Martin, G., Molina, E., Rockmore, C., Stacy, B., Svensson, J. \& Wane, W. (2017). What Do Teachers Know and Do? Does It Matter? Evidence from Primary Schools in Africa. Policy Research Working Paper No. 7956, World Bank. 137. Retrieved 3 August 2020 from http://econ.worldbank.org

Carbonneau, K.J., Marley, S.C., \& Selig, J.P. (2013). A meta-analysis of the efficacy of teaching mathematics with concrete manipulatives. Educational Psychology, 105/2, 380-400. Retrieved 3 August 2020 from 10.1037/a0031084

Carbonneau, K.J., Zhang, X., \& Ardasheva, Y. (2018). Preservice educators' perceptions of manipulatives: the moderating role of mathematics teaching efficacy. School Science and Mathematics, 1-10. Retrieved 3 August 2020 from $10.1111 /$ ssm. 12298

Child, K. (2013, May 6). Teachers are clueless. TimesLive. Retrieved 6 August 2013 from https://www.timeslive.co.za/news/south-africa/2013-05-06-teachers-are-clueless/ 
Dehghan, F. (2020). Teachers' perspectives of professionalism: A top-down or bottomup decision-making process? Professional development in education, 46(1), 1-10. Retrieved 23 March 2020 from Doi: 10.1080/19415257.2020.1725597

Department of Basic Education (DBE). (2011). Mathematics: Curriculum and Assessment Policy Statement (CAPS). Grades 4-6. Department of Basic Education. Pretoria.

Foley, A. E., Herts, J.B., Borgonovi, F., Guerriero, S., Susan Levine, S.C. \& Beilock, S.L. (2017). The Math Anxiety-Performance Link: A Global Phenomenon. Current Directions in Psychological Science, 26(1). 52-58. Retrieved 3 August 2020 from https://doi.org/10.1177/0963721416672463

Freire, P. (1970). Pedagogy of the Oppressed (30 ${ }^{\text {th }}$ Anniversary Edition), London: Bloomsbury.

Gemeda, F.T., Fiorucci, M., and Catarci, M. (2014). Teachers' professional development in schools: Rhetoric versus reality. Professional Development in Education, 40(1), 71-88. Retrieved 14 July 2014 from Doi: $10.1080 / 19415257.2012 .759988$

George, M.J., Kolobe, M., \& Moru, E.K. (2018). Exploring the mathematics and science subject matter content in the primary school level in Lesotho teachers. International Journal of Science and Technology Educational Research, 9(2), 9-17. Retrieved 3 August 2020 from Doi: 10.5897/IJSTER2017.0442

Gore, J., and Rosser, B., (2020). Beyond content-focused professional development: Powerful professional learning through genuine learning communities across grades and subjects. Professional Development in Education, 46(1), 1-16. Retrieved 7 April 2020 from Doi: 10.1080/19415257.2020.1725904

Hidayah, I., Dwijanto, A. \& Istiandaru. (2018). Manipulatives and question series for elementary school mathematics teaching on solid geometry, International Journal of Instruction, 11(3), 649-662. Retrieved 5 April 2020 from https://doi.org/10.12973/iji.2018.11344a

Institute of Development Studies. (2013). Participatory Methods. Retrieved 5 April 2013 from https://www.ids.ac.uk/publications/participatory-methods-website/

Jita, L. C., \& Ige, O. A. (2019). South African teachers' mathematical knowledge: Reflections from Short Learning Intervention Programme (SLIP). Problems of Education in the 21 $1^{\text {st }}$ Century, 77(6), 705-721. Retrieved 3 August 2020 from https://doi.org/10.33225/pec/19.77.705

Jita, L. C., \& Mokhele, M. L. (2014). When teacher clusters work: Selected experiences of South African teachers with the cluster approach to professional development. South African Journal of Education, 34(2), 1-15. Retrieved 3 August 2020 from http://www.sajournalofeducation.co.za 
Larbi, E., \& Mavis, O. (2016). The use of manipulatives in mathematics education, Journal of Education and practice, 7(36), 53-61.

Ma, L. (2010). Knowing and teaching elementary mathematics: Teachers' understanding of fundamental mathematics in China and the United States. (Anniversary Edition). London: Routledge.

Mirza, A., \& Hussain, N. (2018). Performing below the targeted level: An investigation into KS3 pupils' attitudes towards mathematics. Journal of Education and Educational Development, 5(1), 8-24.

Neuman, W.L. (2014). Social Research Methods: Qualitative and Quantitative Approaches ( $7^{\text {th }}$ edition). New York: Pearson Education.

OECD. (2009). Creating effective teaching and learning environments: First results from TALIS. Paris: OECD. Retrieved 17 August 2020 from http://www.oecd.org/education/preschoolandschool/43023606.pdf.

Ozlem, S., \& DiAngelo, R. (2017). Is Everyone Really Equal? An Introduction to Key Concepts in Social Justice. ( $2^{\text {nd }}$ edition). Columbia: Teachers College Press Columbia University.

Reddy, V., Visser, M., Winnaar, L., Arends, F., Juan, A. Prinsloo, C.H., \& Isdale, K. (2016). Highlights of mathematics and science achievement of Grade 6 South African learners. Pretoria: Human Research Council.

Salami, I.A., \& Okeke, C.I.O. (2017). Transformation and decolonisation of mathematics education for sustainable development: A case study of its learning trend in Nigeria. Perspectives in Education, 35(2), 45-59. Retrieved 3 April 2020 from http://dx.doi.org/10.18820/2519593X/piev35/2.4

Shirvani, H. (2015). Pre-service elementary teachers' mathematics content knowledge: Predictor of sixth graders' mathematics performance. International Journal of Instruction, 8(1), 133-142.

Smith, P., Ladewig, M., \& Prinsley, R. (2018). Improving the mathematics performance of Australian students. Office of the Chief Scientist Occasional Paper, July 2018. Australian Government, 1-8.

Strom, J. (2009). Manipulatives in mathematics instruction. A research paper submitted to the Department of Mathematics and Computer Science. Bemidji State University.

Syafriafdi, N., Fauzan, A. Arnawa, I.M., Anwar,S., \& Widada, W. (2019). The Tools of Mathematics Learning Based on Realistic Mathematics Education Approach in Elementary School to Improve Math Abilities. Universal Journal of Educational Research, 7(7), 1532-1536. Retrieved 3 August 2020 from 10.13189/ujer.2019.070707

Venkat, H., \& Spaull, N. (2015). What do we know about primary teachers' mathematical content knowledge in South Africa? An analysis of SACMEQ 2007. International Journal of Educational Development, 41, 121-130. Retrieved 3 August 2020 from https://doi.org/10.1016/j.ijedudev.2015.02.002 